\title{
Bur open Risk factors for injury mortality in rural Tanzania: a secondary data analysis
}

\author{
Kenneth Ayuurebobi Ae-Ngibise, ${ }^{1}$ Honorati Masanja, ${ }^{2}$ Ronel Kellerman, ${ }^{3}$ \\ Seth Owusu-Agyei ${ }^{1}$
}

To cite: Ae-Ngibise KA, Masanja H, Kellerman R, et al. Risk factors for injury mortality in rural Tanzania: a secondary data analysis. BMJ Open 2012;2:e001721. doi:10.1136/bmjopen-2012001721

\section{- Prepublication history for this paper are available online. To view these files please visit the journal online (http://dx.doi.org/10.1136/ bmjopen-2012-001721).}

Received 9 July 2012 Accepted 27 September 2012

This final article is available for use under the terms of the Creative Commons Attribution Non-Commercial 2.0 Licence; see http://bmjopen.bmj.com

\section{ABSTRACT}

Background: Injuries rank high among the leading causes of death and disability annually, injuring over 50 million and killing over 5 million people globally. Approximately $90 \%$ of these deaths occur in developing countries.

Objectives: To estimate and identify the risk factors for injury mortality in the Rufiji Health and Demographic Surveillance System (RHDSS) in Tanzania.

Methods: Secondary data from the RHDSS covering the period 2002 and 2007 was examined. Verbal autopsy data was used to determine the causes of death based on the 10th revision of the International Classification of Diseases (ICD-10). Trend and Poisson regression tests were used to investigate the associations between risk factors and injury mortality. Results: The overall crude injury death rate was 33.4 / 100000 population. Injuries accounted for $4 \%$ of total deaths. Men were three times more likely to die from injuries compared with women (adjusted IRR (incidence risk ratios) $=3.04, p=0.001,95 \% \mathrm{Cl}(2.22$ to 4.17$))$. The elderly (defined as $65+$ ) were 2.8 times more likely to die from injuries compared with children under 15 years of age (adjusted IRR $=2.83, \mathrm{p}=0.048,95 \% \mathrm{Cl}$ (1.01 to 7.93)). The highest frequency of deaths resulted from road traffic crashes.

Conclusions: Injury is becoming an important cause of mortality in the Rufiji district. Injury mortality varied by age and gender in this area. Most injuries are preventable, policy makers need to institute measures to address the issue.

\section{INTRODUCTION}

Injuries have traditionally been regarded as 'unavoidable' accidents. In recent decades however, there is a shift in perspective and injuries are being recognised as preventable events. $^{1}$

Injury mortality is a major global public health problem, accounting for $9 \%$ of mortality and $16 \%$ of all disabilities annually. ${ }^{2}$ The global rate of unintentional injuries was $61 / 100000$ populations/year and road traffic injuries made up the largest proportion of unintentional injury deaths $(33 \%)$. When standardised per 100000 population, the

\section{ARTICLE SUMMARY}

\section{Article focus}

- To identify the risk factors for injury mortality in the Rufiji district.

- To estimate the proportion of injury mortality within the Rufiji district.

- To identify the cause-specific mortality related to injuries.

- To determine the trends of injury mortality in the Rufiji district.

Key messages

- Injury is becoming an important cause of mortality in the Rufiji district.

- Injury mortality varied by age and gender in this area.

- Road traffic crashes were the leading cause of injury deaths.

Strengths and limitations of this study

- The sample size was a true representation of the study area and was large enough to give the study a statistical power. We used person-years of observation (PYO) method which is a more accurate measure of time-to-event compared to mid-year population estimates. The study used longitudinal data collected and updated periodically and thus able to monitor demographic change.

- Despite rigorous training and thorough fieldwork operations and quality control measures, it is difficult to comprehensively evaluate the completeness and accuracy of HDSS data given the absence of a gold standard against which to measure findings. Some of the exposure variables for injury mortality in this study had relatively small number of deaths for each injury aetiology. Socioeconomic status as a risk factor for injury mortality had missing data for half of the study participants and could have a potential impact on the findings.

death rate was almost double in low and middle income countries (LMIC) compared with high-income countries (65 vs 35 per 100000 ), and the rate of disability-adjusted life-years is more than triple in LMIC (2398 vs 774 per 100000$){ }^{3}$ 
In LMIC, injuries are growing in significance because of the demographic and socioeconomic transitions that have characterised their development in recent decades. ${ }^{4}$ Of an estimated 5.4 million people worldwide who died from injuries in 2005 , over $90 \%$ occurring in low-income and middle-income countries. ${ }^{5}$

Although non-communicable diseases were responsible for nearly $60 \%$ of deaths globally in 2001 compared with 9\% due to injury mortality, the years of life lost (YLL) proportional to injuries is much higher, at $12 \%$, compared with $40 \%$ for chronic diseases. ${ }^{6}$ According to the Global Burden of Disease 2000 data, over five million people (83.7/100 000 population) died worldwide from injuries in $2000 .^{7}$

In many developing countries, injuries have a significant impact on the health of populations and are rapidly becoming increasingly recognised as a major cause of death and disability. Eight of the 15 leading causes of death for people aged 15-29 years were injury-related including both intentional and unintentional deaths. ${ }^{8} 9$ For every death that results from injury, dozens of hospitalisations, hundreds of emergency department visits and thousands of doctors' appointments occur. It is projected that by 2020 , injuries will compete with infectious diseases as a major source of mortality and morbidity in the developing world. ${ }^{10}$

Modernisation has reportedly been associated with increased mortality from injury. A study in Tanzania reported that as populations grow and become more mobile, a large proportion of adults are at higher risk for injuries than in the past. Similarly, a 2002 survey of 7035 rural and 8188 urban households in Tanzania found that $22.5 \%$ and $4.3 \%$ persons reported injuries, respectively. Although the overall incidence was higher in the rural area, the incidence of major injuries (> or=30 disability days) was similar in both areas. ${ }^{11} 12$ Male children were mainly affected in a total of 342 burned children in Northwestern Tanzania and children aged 2 years and under were the majority, accounting for $45.9 \%$ of cases. ${ }^{13}$

The descriptive epidemiology of injury mortality in Africa and other low-income countries is poorly understood. As a result, accurate data on the vital statistics about injury mortality is not well documented. ${ }^{12}$

To add to knowledge on injury mortality in the Africa, this study examined the distribution of injury deaths, gender-specific and age-specific trends and other risk factors associated with injury mortality in rural Tanzania.

\section{METHODOLOGY}

\section{Study design and setting}

The research design comprised a cross-sectional study of injury mortality among the population of residents in the Demographic Surveillance Area (DSA) of the RHDSS between 2002 and 2007.

The study was conducted in the Rufiji Health and Demographic Surveillance System (RHDSS) area, one of the Demographic Surveillance Centres in Tanzania. The INDEPTH (International Network for the Demographic Evaluation of Populations and their Health) Network's monograph on mortality defines a demographic surveillance system (DSS) as a set of field and computing operations to handle the longitudinal follow-up of welldefined entities or primary subjects (individuals, households and residential units) and all related demographic and health outcomes within a clearly circumscribed geographic area.

The RHDSS area extends from 7.470 to 8.030 south latitude and 38.620 to 39.170 east longitude. The area is located in the Rufiji district, about $178 \mathrm{~km}$ south of Dar es Salaam. The RHDSS operates in 6 contiguous wards and 31 villages (about $60 \mathrm{~km}$ long $\times 30 \mathrm{~km}$ wide) and covers an area of $1813 \mathrm{~km}^{2}$. The total population under demographic surveillance is about 85000 . Women $(52 \%)$ outnumber men $(48 \%)$ in the Rufiji DSA. The average household size is about four to eight persons.

According to The United Republic of Tanzania's 2002 Population and Housing Census General Report, the population of Rufiji district was approximately 203102 (98 398 men and 104704 women) with an annual growth rate of $2.3 \%$. The mean household size for the whole district was approximately five persons. ${ }^{14}$ The district is largely rural, though the population is clustered around Utete (District headquarters), Ikwiriri, Kibiti and Bungu townships. All the last three townships are within the HDSS area. Islam is the dominant religion, followed by Christianity and then African traditional believers. Kiswahili is the main language spoken by the inhabitants.

\section{Data source}

The RHDSS cause-specific mortality data was the primary data source for this study. The RHDSS prospectively records longitudinal data on household demographics and is updated every 4 months. The variables contained in the RHDSS injury mortality database includes basic demographic information such as date of birth, personal identification number, gender, occupation, marital status, socoieconomic status, migration, injury specific cause of death, date of death, place of death and year of death.

The HDSS was established to provide sentinel data through continuous surveillance of households and members within households in cycles with the aim of gathering information on health and demographic data to inform health policy and planning and to evaluate/ monitor the impact of health reforms.

\section{Variables and definitions}

Injury mortality was the outcome variable of interest. It included all deaths resulting from injuries, whether unintentional or intentional in the Rufiji surveillance area between 2002 and 2007. The causes of deaths in the DSA had already been determined by the physicians using the verbal autopsy data, in line with the 
International Classification of Diseases ICD-10. ${ }^{15}{ }^{16}$ Using the verbal autopsy data to diagnose cause of death have been validated..$^{17} 18$ The cause of death was usually based on both remote and immediate factors leading to death.

A death outcome was classified as injury death when it occurred due to any one or combination of the following: animal bites, drowning, falls, firearm, fire/burns, road transport crash, homicide and suicide (poison, hanging). The outcome variable was classified as positive for all injury-related deaths and negative for individual alive in a particular year. The total person-years observed was the summation of all the individual time at risk of injury mortality from 2002 to 2007 .

\section{Case identification}

Injury mortality data from the RHDSS database was used for the analysis.

\section{Data collection}

Data were extracted from the RHDSS for the period 2002-2007.

\section{Data analysis}

Principal component analysis (PCA) was used to construct a socioeconomic index for each household. ${ }^{19} 20$ Households were categorised into high, medium and low socioeconomic status (SES) based on the average number of household assets owned by the study participants as well as the environmental and household characteristics. Some of the assets included in the construction of the PCA were ownership of goats, cattle, sheep, houses, cars, chicken and televisions. The personyears of observation (PYO) was computed for all study participants from the individual member information table and the migration table. This takes into consideration the movements of participants, the event file which records all the event history that have happened to individual members, and the interval file which is the start and end date of the study from which the person time of contribution is generated. The total person-years observed was the summation of all the individual time at risk of injury mortality from 2002 to 2007.

Univariate and multivariate Poisson regression analysis was performed using STATA V.10 to assess the association between the risk factors and injury mortality. Not every study participant was observed for the same length of time and Poisson regression model allows for this through something called an offset whereby every individual contribution of time is account for in the analysis.

$\chi^{2}$ Test for trend was used to examine trends and patterns in injury mortality. All tests for significant associations were based on $\mathrm{p}$ values at $5 \%$ significance level.

The descriptive statistical analysis comprised an examination of trends and patterns in injury mortality by age, gender, SES and the identification of other risk factors associated with injury mortality. The analytic component involved the measurement of the association between age, gender, socioeconomic, education, occupation, marital status (for individuals aged 15 years only) and injury mortality. Poisson regression analysis was used because it takes into account each participant's contribution of time throughout the entire study duration.

\section{Ethics}

Anonymity and confidentiality was ensured by replacing any potential personal identification of the study participants with unique reference codes. Ethical approval was obtained from the Human Research Ethics Committee (Medical) of the University of the Witwatersrand. Ethics clearance was also obtained from the Ifakara Health Institute-Institutional Review Board for the primary study data collection.

\section{RESULTS}

\section{Description of the study population}

Table 1 presents the sociodemographic characteristics of the study population. There were 119271 residents contributing 592324.03 PYO over the study period. There were slightly more women $(52.9 \%)$ compared with men $(47.1 \%)$. Children younger than 15 years of age constituted the largest group $50515(42.4 \%)$. Half of the study population $(60588(50.8 \%))$ had no formal education and over a third of the study participants (37.3\%) were farmers. Household wealth profile using PCA revealed that $18971(35.5 \%)$ were classified as low SES. In terms of conjugal status, $20675(18.6 \%)$ participants were not married while $40554(36.5 \%)$ ever married.

A total of 4471 deaths were recorded over the study period, of which 198 were classified as injury deaths. Majority of the injury deaths were men $140(71 \%)$ vs 58 $(29 \%)$. Most of the injury deaths were unintentional $(90 \%)$.

The overall injury death rate was $33.4 / 100000$ population. Injury death rate (49.7) was more than double in men (95\% CI 42.1 to 58.6) compared with women, 18.7 (95\% CI 14.4 to 24.2$) \mathrm{p}=0.001$. The elderly (defined as any resident $>65$ years of age) experienced the highest injury mortality 128.7 (95\% CI 98.9 to 167.7). Most important exposure variable(s) were associated with injury mortality. It is of interest to note that tertiary education level participants constituted a small proportion of the population $(n=757$, number of deaths $=3$ ) compared with the other categories.

The injury deaths among retired workers was also higher (273/100 $000 \mathrm{PYO})$, compared with casual workers (62/100 $000 \mathrm{PYO})$, the unemployed (56/100 000 personyears) and farmers (41/100 000 population). There was no evidence of a difference in injury mortality by SES though the individuals in the lowest SES category had the highest rates compared with the other groups. Those who ever married had death rate of 57/100 000 population, compared with 29/100 000 population among those who never married. 
Table 1 Descriptive statistics of the study population by study variables

\begin{tabular}{|c|c|c|c|c|c|c|}
\hline Exposure factor & Frequency & Per cent & Person time & Dead & Rate & $95 \% \mathrm{Cl}$ \\
\hline \multicolumn{7}{|l|}{ Gender } \\
\hline Female & 63042 & 52.9 & 310556.33 & 58 & 18.7 & 14.4 to 24.2 \\
\hline Male & 56229 & 47.1 & 281767.7 & 140 & 49.7 & 42.1 to 58.6 \\
\hline Total & 119271 & & 592324.03 & 198 & 33.4 & 29.1 to 38.4 \\
\hline \multicolumn{7}{|l|}{ Age group } \\
\hline $1-14$ & 50515 & 42.4 & 254938.5 & 40 & 15.7 & 11.5 to 21.4 \\
\hline $15-34$ & 41195 & 34.5 & 192014.21 & 55 & 28.6 & 22.0 to 37.3 \\
\hline $35-64$ & 19480 & 16.3 & 102645.01 & 48 & 46.8 & 35.2 to 62.1 \\
\hline $65^{+}$ & 8081 & 6.8 & 42726.31 & 55 & 128.7 & 98.8 to 167.7 \\
\hline Total & 119271 & & 592324.03 & 198 & 33.4 & 29.1 to 38.4 \\
\hline \multicolumn{7}{|l|}{ Education } \\
\hline Primary & 53024 & 44.5 & 270807.1 & 73 & 27.0 & 21.4 to 33.9 \\
\hline No-formal & 60588 & 50.8 & 293677.2 & 118 & 40.2 & 33.6 to 48.1 \\
\hline Secondary & 4878 & 4.1 & 24250.0 & 4 & 16.5 & 6.2 to 44.0 \\
\hline Tertiary & 757 & 0.6 & 3516.5 & 3 & 85.3 & 27.5 to 264.5 \\
\hline Total & 119247 & & 592250.83 & 198 & 33.4 & 29.08 to 38.4 \\
\hline \multicolumn{7}{|l|}{ Occupation } \\
\hline Student & 4026 & 4.2 & 151544.4 & 12 & 8.0 & 4.5 to 13.9 \\
\hline Unemployed & 27435 & 28.9 & 17878.2 & 10 & 55.9 & 30.1 to 104.0 \\
\hline Retired & 4399 & 4.6 & 12098.2 & 33 & 272.8 & 193.9 to 383.7 \\
\hline Casual & 17377 & 18.3 & 74459.5 & 46 & 61.8 & 46.3 to 82.5 \\
\hline Farming & 35505 & 37.3 & 181796.8 & 74 & 40.7 & 32.4 to 51.1 \\
\hline Other & 6333 & 6.7 & 128472.2 & 23 & 17.9 & $11.9-26.9$ \\
\hline Total & 95076 & & 566249.2 & 198 & 35.0 & 30.4 to 40.2 \\
\hline \multicolumn{7}{|l|}{ Household SES } \\
\hline High & 15989 & 30.0 & 78611.6 & 23 & 29.3 & 19.4 to 44.0 \\
\hline Medium & 18418 & 34.5 & 91127.64 & 38 & 41.7 & 30.3 to 57.3 \\
\hline Low & 18971 & 35.5 & 93664.9 & 43 & 45.9 & 34.1 to 61.9 \\
\hline Total & 53378 & & 263404.14 & 104 & 39.5 & 32.58 to 47.9 \\
\hline \multicolumn{7}{|l|}{ Marital status } \\
\hline Single ( $>15$ years) & 20675 & 18.6 & 102676.6 & 30 & 29.2 & 20.43 to 41.8 \\
\hline Ever married & 40554 & 36.5 & 218805.1 & 125 & 57.1 & 47.9 to 68.1 \\
\hline Single ( $<15$ years) & 49950 & 44.9 & 2616721.0 & 43 & 16.4 & 12.2 to 22.2 \\
\hline Total & 111179 & & 583153.6 & 198 & 33.4 & 29.1 to 38.4 \\
\hline
\end{tabular}

Overview of mortality proportions in Rufiji DSA from 2002 to 2007

Figure 1 shows the distribution of causes of deaths during the study period. Injuries accounted for $4 \%$ of total deaths. The overall mortality was 754.8/100 000 PYO; Malaria (24\%) and cardiovascular diseases (23\%) contribution was similar and accounted for almost half of the total deaths. The other external cause category (15\%) included maternal deaths, specified and unspecified communicable diseases, specified and unspecified acute febrile illnesses, diarrhoeal diseases, meningitis, hepatitis, specified and unspecified acute respiratory infections, tetanus and measles. AIDS and pulmonary tuberculosis $(14 \%)$ were the fourth largest contributors of burden of mortality (figures 2-5).

\section{Distribution of cause-specific injury mortality in the Rufiji DSA}

The types of injury mortality recorded in the study area during the period of analysis included road traffic accident, drowning, burns, homicidal injuries, accidental poisoning, animal bite/attack, falls, suicidal injuries and unspecified external injuries (deaths due to complications of medical and surgical care or being hit by external objects like trees and heavy loads). More than one-quarter of the injury deaths were due to road traffic accidents 56 (28\%), unspecified external injuries accounted for $40(20 \%)$, drowning $32(16 \%)$ and burns 18 (9\%). The lowest injury deaths were attributed to suicide 4 $(2 \%)$ or broadly referred here as intentional injuries.

\section{Estimating the yearly crude death rates (CDR) of injury} from 2002 to 2007

There was a consistent yearly increase in the injury CDR from 2002 to 2005. However, a slight decline was observed between 2005 and 2007 but we found no evidence of this drop in injury mortality. The $\chi^{2}$ for trends test showed no significant difference in proportions of injury deaths among the different years $(\mathrm{p}=0.288)$. 


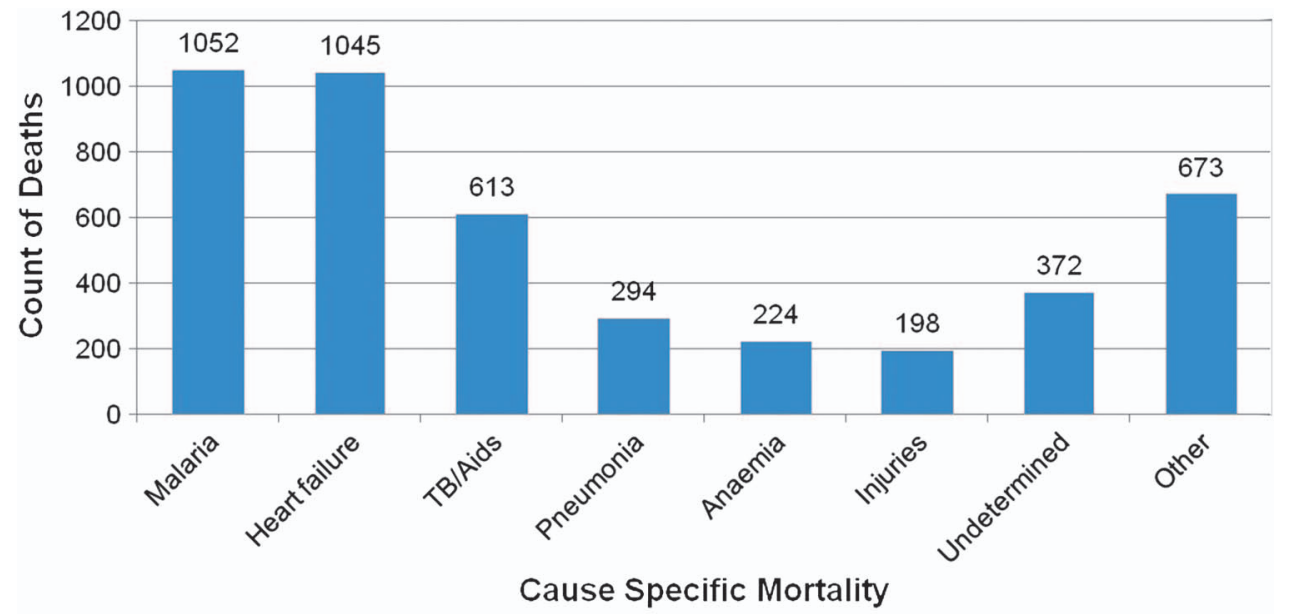

Figure 1 Major causes of mortality in Rufiji Health and Demographic Surveillance System (RHDSS) from 2002 to 2007.

Gender and injury mortality from 2002 to 2007

Injury mortality in men was significantly higher compared with women during the period. Injury mortality increased both in men and women from 2002 to 2005 and then dropped. Men were 2-4 times more likely to die of injuries compared with women. Men were more likely to die from RTAs, external causes and drowning compared to women. On the other hand, women were more likely to die of burns and animal attacks.

\section{Cause-specific injury mortality by gender}

Men were more likely to die in road traffic crashes, other external causes and drowning compared with women. On the other hand, women were more likely to die of burns and animal attacks.

\section{Inferential analysis}

Univariate Poisson regression analysis of risk factors for injury mortality

Univariate and multivariate Poisson regression analyses were carried out to demonstrate the associations between risks factors (gender, age, occupation, education, marital status and SES) and injury mortality. Incidence risk ratios (IRR) were used to measure the strength of the relationships and interpreted as relative risk. The results are presented in table 2.

In the univariate logistic regression analysis model, age, education, gender, marital status and occupation were all significant risk factors for injury mortality (table 2).

In the multivariable logistic regression analysis model, however, three variables were significant risk factors associated with injury mortality having adjusted for the variables in the univariate model. These are gender, age and occupation.

Adjusted for age, occupation, education and marital status, men (IRR=3.04; 95\% CI 2.22 to 4.17 ), the elderly $($ IRR $=2.83 ; 95 \%$ CI 1.01 to 9.93$)$ and being unemployed (IRR=8.57; 95\% CI 3.26 to 22.48) were all found to be significant risk factors for injury mortality (table 2).

\section{DISCUSSION}

\section{Proportion of injury mortality}

This study presented a population-based data on the proportion of injury-related deaths, the cause-specific injuries as well as the risk factors for injury mortality from a predominantly rural area in Tanzania from 2002 to 2007 .

Injuries remain a threat to human existence globally, especially in developing countries. Injury mortality accounted for $4 \%$ of total deaths during the study period. A study in South Africa reported that $8.9 \%$ of deaths were injury-related and homicide, road traffic crashes and suicide were the major causes of injury mortality. The study analysed data on 133483 individuals with 717584.6 person-years of observation resulted in 11467 deaths. ${ }^{21}$

\section{Risk factors for injury mortality}

The findings in this study are consistent with those found in other studies; generally men were more likely to experience injury mortality compared with women. Globally, injury mortality among men is twice of that among women and men in Africa and Europe have the highest injury-related death rates. ${ }^{1}$ In South Africa, the male-female injury mortality ratio in 2008 was $3.3: 1 .^{22}$ It also reflects the results from a study conducted by Moshiro et $a l^{11}$ in Dar es Salaam, Hai and Morogoro districts in Tanzania that documented injury death rates being approximately 3 times higher among men compared to women. ${ }^{23} 24$ The high male injury death rate in this rural setting might be explained by the genderspecific roles where men are more likely to perform the risky jobs like fishing, manual farming and road traffic-related activities like driving.

Age was also associated with injury mortality. The elderly were strongly associated with higher injury death rates compared with the younger age groups. This finding is similar to what was reported by Lopez et $a l^{6}$ which attributed one-quarter of injury deaths to those aged between 15 and 59 years. The assertion that injury 
Figure 2 Distribution of injury cause-specific mortality in Rufiji Health and Demographic Surveillance System (RHDSS).

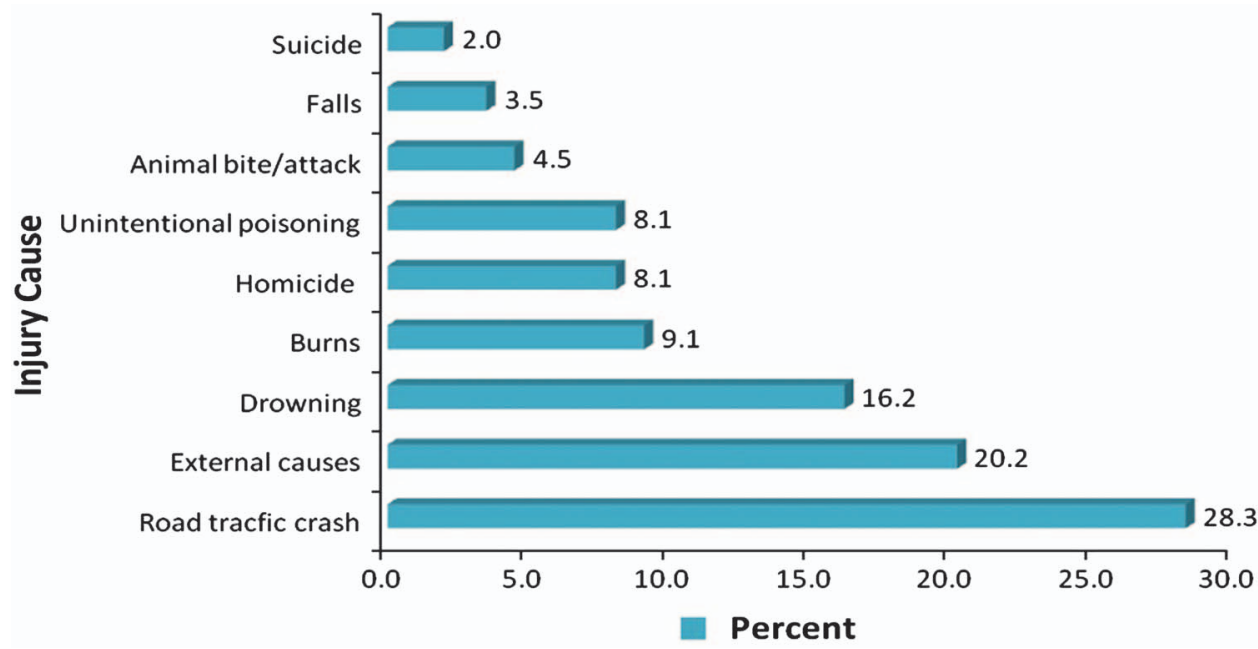

death rates increased with age is similar to the findings by Moniruzzaman and Andersson, ${ }^{25}$ which reported that in LMIC, there is a direct relationship between age and injury mortality such that as age increases, the risk for injury mortality increases.

In this study, those who were in active employment had lower risk of injury mortality. This compares with the study by Garrib et al, ${ }^{21}$ which found that full-time employment was significantly associated with lower mortality in South Africa.

A couple of studies have demonstrated that increasing SES has a strong inverse association with the risk of fatal injuries; more than $80 \%$ of childhood burns have been reported to occur among low socioeconomic groups. ${ }^{26-29}$ This study did not find sufficient evidence to suggest that household wealth was a key risk factor for injury mortality. This could be attributed to the fact that SES information was not available for half of the households who were included in this analysis. Furthermore, Rufiji DSA is typically rural and almost homogeneous in terms of wealth index; there is very little variation in items possession, hence, no significant difference in SES between the high and low groups.

\section{Types of injuries}

Among the two broad types of injuries, $90 \%$ were unintentional. The high unintentional injury deaths has

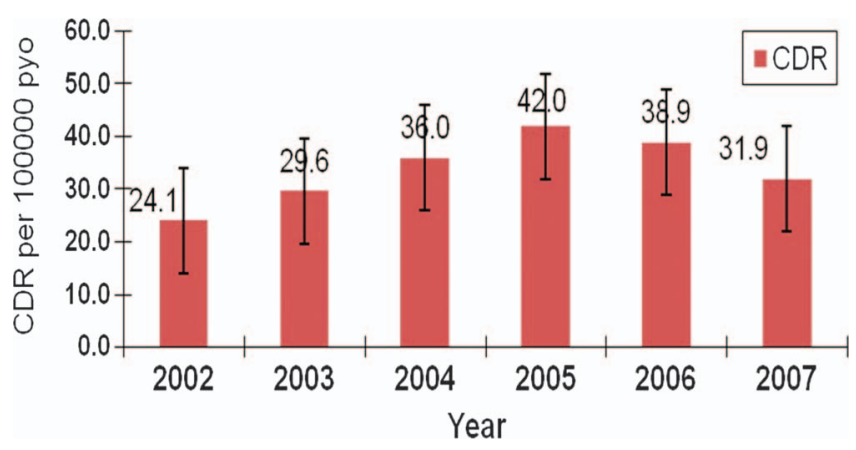

Figure 3 Trend of injury mortality from 2002 to 2007. been reported in studies in other parts of Tanzania. ${ }^{11}$ The role of road traffic accident as the leading cause of injury mortality in this study is consistent with other injury deaths in other African countries, including Kenya and Ghana. ${ }^{11} 30{ }^{31}$ Death rates because of road traffic crashes were again significantly higher in men than women in all age groups, for both pedestrians and vehicle occupants. $^{21}$ risk of injury mortality. These include poverty, lack of education, unemployment, alcohol and substance abuse, interpersonal conflict, intimacy and power. ${ }^{32} 33$

Injuries related to burns from this analysis indicated that women were more likely to die compared to men. Other studies in Africa reported that men were more likely to die of burn fatalities and that young children and the elderly are the most vulnerable. ${ }^{1} 293435$ One possible explanation for the difference in findings may be due to the settings. Whereas those studies were conducted in urban settlements, this study was conducted in a typically rural setting where cooking is seen as the birthright responsibility of women.

Drowning was among the main causes of injury mortality in this study. Studies have shown that Africa had the highest drowning death rate (13.1/100 000 PYO) and men had higher drowning death rates than women for all ages and in all regions and was more pronounced in children up to 14 years. $^{7}$ In this study, however, most of the drowning fatalities occurred in young (15-34) and middle-aged (35-54) adults. In the Rufiji DSA, most

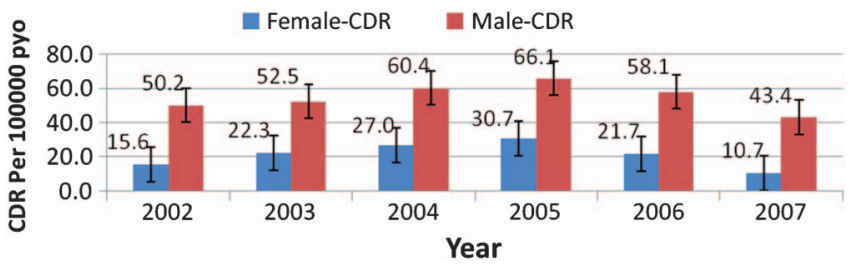

Figure 4 Trend of injury mortality by gender from 2002 to 2007.
Many other factors are known to be associated with 


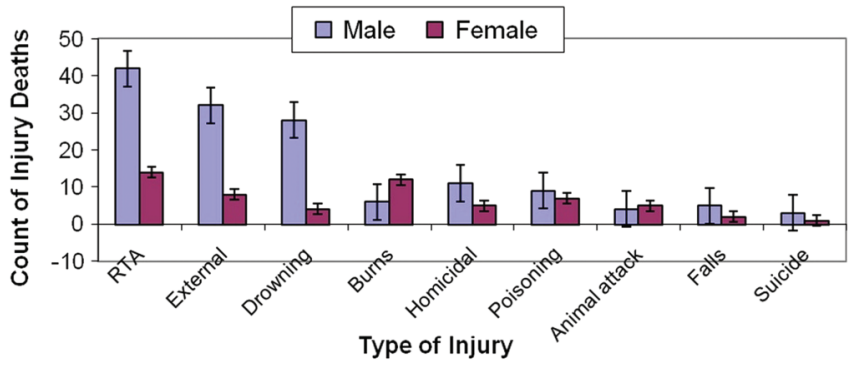

Figure 5 Cause-specific injury by gender.

of the people are engaged in subsistence farming and fishing activities with the proximity of the Rufiji River as a possible influencing factor. For example, most of the time men are the fishermen who at times engage in fishing without life jackets. There are no enforced laws on fishing. Fishing activities need to be regulated to save lives. In some developed countries, however, there are laws regulating recreational swimmers and fishermen which prove a safety measure against drowning. ${ }^{36} 37$

We documented more male deaths from unintentional poisoning compared with female deaths, reflecting those reported in other studies which indicate that the highest poisoning death rates were among the male populations in the low-income and middle-income countries; over $60 \%$ of the global mortality due to poisoning occurs among adolescents and adults aged between 15 and 59 years. ${ }^{38}$

Middle-aged men reported to have died more of homicidal injuries compared with women is consistent with global report which shows that more than threequarters $(77 \%)$ of homicide deaths in 2000 were among men with the highest levels of homicide occurring among men 15-29 years of age and closely followed by those who were $30-44$ years old. ${ }^{38}$ Results from the South African National Injury Mortality Surveillance System (NIMSS) in 2000 also indicate that homicidal injuries contributed $36 \%$ of all injury deaths, ${ }^{39}$ and that homicide continues to be the leading cause of premature death among South African men. ${ }^{40}$ In another study, higher death rates were reported for homicide deaths among men in all age groups especially young adults aged $30-39$ years. ${ }^{21}$

In related studies, young adult men are at the highest risk of injury-related mortality and comprised the majority of perpetrators as well as victims of interpersonal violence. $^{33} 41$

Suicide was the lowest rate of external cause of death in this community even though suicide was the most

\begin{tabular}{|c|c|c|c|c|c|c|}
\hline \multirow[b]{2}{*}{ Factor } & \multicolumn{3}{|c|}{ Univariate model $(95 \% \mathrm{Cl})$} & \multicolumn{3}{|c|}{ Multivariate model $(95 \% \mathrm{Cl})$} \\
\hline & IRR & $\mathbf{C l}$ & p Value & $\overline{\mathbf{I R R}}$ & $\mathbf{C l}$ & p Value \\
\hline \multicolumn{7}{|l|}{ Gender } \\
\hline Female & $1^{*}$ & 1.96 to 3.61 & $<0.001$ & $1^{*}$ & 2.22 to 4.17 & $<0.001$ \\
\hline Male & 2.66 & & & 3.04 & & \\
\hline \multicolumn{7}{|l|}{ Age groups } \\
\hline $1-14$ & $1^{*}$ & 1.22 to 2.74 & 0.004 & $1^{*}$ & 0.38 to 2.52 & 0.972 \\
\hline $15-34$ & 1.83 & 1.96 to 4.53 & $<0.001$ & 0.98 & 0.48 to 3.75 & 0.582 \\
\hline $35-64$ & 2.98 & 5.46 to 12.33 & $<0.001$ & 1.34 & 1.01 to 7.93 & 0.048 \\
\hline $65^{+}$ & 8.20 & & & 2.83 & & \\
\hline \multicolumn{7}{|l|}{ Occupation } \\
\hline Student & $1^{*}$ & 3.05 to 16.35 & $<0.001$ & $1^{*}$ & 1.81 to 9.42 & $<0.001$ \\
\hline Farming & 5.14 & 4.13 to 14.73 & $<0.001$ & 4.13 & 3.25 to 16.66 & $<0.001$ \\
\hline Casual & 7.80 & 2.79 to 9.46 & $<0.001$ & 7.36 & 3.26 to 22.48 & $<0.001$ \\
\hline Unemployed & 7.06 & 17.79 to 66.70 & $<0.001$ & 8.57 & 12.53 to 63.71 & $<0.001$ \\
\hline Retired & 34.45 & & & 28.26 & & \\
\hline \multicolumn{7}{|l|}{ Marital status } \\
\hline Single (>15 years) & $1^{*}$ & 1.31 to 2.91 & $<0.001$ & $1^{*}$ & 0.64 to 1.83 & 0.776 \\
\hline Ever married & 1.96 & 0.35 to 0.90 & 0.016 & 1.08 & 0.59 to 3.57 & 0.423 \\
\hline Children (<15 years) & 0.56 & & & 1.45 & & \\
\hline \multicolumn{7}{|l|}{ Education } \\
\hline Primary & $1^{*}$ & 1.11 to 2.00 & 0.007 & $1^{*}$ & 0.87 to 1.79 & 0.230 \\
\hline No-formal & 1.49 & 0.22 to 1.67 & 0.339 & 1.25 & 0.21 to 1.62 & 0.306 \\
\hline Secondary & 0.61 & 1.00 to 10.04 & 0.050 & 0.59 & 0.37 to 3.86 & 0.769 \\
\hline Tertiary & 3.16 & & & 1.19 & & \\
\hline \multicolumn{7}{|l|}{ Household SES } \\
\hline High & $1^{*}$ & & & & & \\
\hline Medium & 1.43 & 0.85 to 2.39 & 0.180 & & & \\
\hline Low & 1.58 & 0.95 to 2.60 & 0.081 & & & \\
\hline
\end{tabular}

$1^{\star}$, Reference group.

IRR, incidence risk ratios; SES, socioeconomic status; 
common cause of injury death and was more pronounced in men compared with women in a South African study. ${ }^{21}$

In many Western countries, suicide is commonly the leading cause of death. Suicide rates have increased during the last four decades despite prevention efforts and there is marked geographic variability in suicide rates, with the highest rates being found in Eastern Europe and the lowest in Muslim and Latin American countries. This unevenness in suicide rates has not been adequately established. Majority of studies in the psychiatric literature have approached the analysis of risk factors and correlates of suicidal behaviours from a clinical perspective in developed countries where clinical studies have established that psychiatric disorders are the most important contributing factor to suicide. ${ }^{42-44}$

\section{Trends of injury mortality}

What is of greatest concern is the increasing trend in injury mortality over time in the studied area. The increase could be attributed to the bad road network. According to the US State Department, many rural roads in Tanzania are virtually impassable, as seasonal washouts are commonplace. ${ }^{45}$ It is encouraging, however, that a gradual decreasing trend was observed getting to the tail end of the studied period. The reversal trend could be attributed to the reconstruction of the Dar es Salaam Rufiji road which was completed in 2005. It is recommended that further analysis be carried out on the data collected from 2008 to ascertain whether the current deaths attributed to road traffic crashes is generally on the increase or decrease.

\section{CONCLUSION AND RECOMMENDATION}

In Rufiji DSA, injuries remain an important cause of death but the extent of variation by age group in the overall level of risk as well as risk from individual causes suggest that interventions tailored more to age group and gender specific would maximise prevention efforts.

In particular, the threats from road traffic accidents in the middle-aged adults and the elderly, drowning in young adults and children, burns as well as animal attack in children, homicide in young adults, suicide in middle adults, and accidental poisoning in all age groups need urgent attention and consideration. Also, burns as well as animal attacks in women, and road traffic injuries, drowning, falls, homicidal or assault, accidental poisoning in men needs targeted interventions. This study has revealed that in the Rufiji DSA, there are significant disparities in injury death rates by gender, age-group and occupation. The leading cause of injury mortality has been noted as RTAs. Men continue to have higher injury death rates than women across all age groups. There is a high need for targeted intervention for men in the district.

With the demonstrated increasing trend of injury mortalities in most developing countries, an injury prevention curriculum has to be introduced in the education portfolio and this should be across the various levels of the educational levels for awareness creation. The Health Sector needs to include road safety in their health promotion and disease prevention activities. Road safety education has been noted as one of the key tools used to successfully reduce fatalities on the roads. There is the need for educational campaigns at various levels to create public awareness of the need for safety and precautionary measures to minimise or prevent injuries.

Two of the three factors (age and gender) associated with injury mortality are frequently found in other disease processes and are largely thought to be nonmodifiable. However, intervention tailored to these groups can improve and maximise prevention policies.

\section{Weakness of the HDSS}

Some of the exposure variables for injury mortality in this study had relatively small number of deaths for each injury aetiology. Examples are injury from burns, poisoning, and homicide. This makes the discussions not very conclusive. Therefore, the existing RHDSS data does not contain sufficient information to accurately and adequately estimate the risk factors for injury mortality. Also, the classification of cause-of-death as the assignment of ICD-10 coding can be quite complex, particularly for poisoning. SES as a risk factor for injury mortality had missing data for half of the study participants and could have a potential impact on the findings. Nevertheless, SES was not the main interest of this study. Another possible limitation of verbal autopsy data recall bias and miss or under reporting of some vital events.

Notwithstanding the thorough training regarding data collection in the field adopted by the HDSS, the data are yet to be assessed for its scientific validity as reported by Kahn $e t a l^{46}$

\section{Strengths of the HDSS}

The sample size was a true representation of the study area and was large enough to give the study a statistical power. We used PYO method which is a more accurate measure of time-to-event compared to mid-year population estimates. The study used longitudinal data collected and updated periodically and thus able to monitor demographic change. The added advantage of the HDSS is that it prospectively follows the whole community to monitor demographic change. ${ }^{47}$

Acknowledgements The authors are grateful to the INDEPTH (International Network for the Demographic Evaluation of Populations and their Health) network for the sponsoring the primary author to carry out this study and also allowed for presentation of an earlier version of the paper at the INDEPTH Scientific Conference in Accra, Ghana in September 2010 and to attend a scientific writing workshop in Ho, Ghana in January 2011. We also render our sincere gratitude to the director and staff of Ifakara Health Institute for the provision of the injury mortality data for this analysis and also to the lecturers and staff of the School of Public Health, University of the Witwatersrand, for good coordination of the programme. 
Contributors KA conceived of and developed the proposal under the supervision of RK. KA performed the statistical analysis under the supervision of HM. KA drafted the manuscript which was reviewed by OA. All authors read and approved the final manuscript.

Funding The INDEPTH Network provided financial assistance for this study. Competing interests None.

Ethics approval The Human Research Ethics Committee (Medical) of the University of the Witwatersrand.

Provenance and peer review Not commissioned; externally peer reviewed. Data sharing statement The data remains the property of the Rufiji Health and Demographic Surveillance System.

\section{REFERENCES}

1. Peden $M$, Hyder A. Road traffic injuries are a global public health problem. BMJ 2002;324:1153.

2. WHO. Violence, injuries, and disability: Biennial 2006-2007 Report. Geneva, Switzerland: World Health Organization, 2008.

3. Chandran A, Hyder AA, Peek-Asa C. The global burden of unintentional injuries and an agenda for progress. Epidemiol Rev 2010;32:110-20.

4. McGee K, Sethi D, Peden M, et al. Guidelines for conducting community surveys on injuries and violence. Inj Control Saf Promot 2004;11:303-6.

5. Borse NN, Hyder AA. Call for more research on injury from the developing world: results of a bibliometric analysis. Indian $\mathrm{J}$ Med Res 2009;129:321-6.

6. Lopez AD, Mathers CD, Ezzati M, et al. Global and regional burden of disease and risk factors, 2001: systematic analysis of population health data. Lancet 2006;367:1747-57.

7. Peden MM, McGee K. The epidemiology of drowning worldwide. Inj Control Saf Promot 2003:10:195-9.

8. Al-Kharusi W. Update on road traffic crashes: progress in the Middle East. Clin Orthop Relat Res 2008:466:2457-64.

9. Peden M. Global collaboration on road traffic injury prevention. Int $J$ Inj Contr Saf Promot 2005;12:85-91.

10. Ahsan Karar Z, Alam N, Kim , et al. Epidemiological transition in rural Bangladesh, 1986-2006. Glob Health Action 2009;2.

11. Moshiro C, Mswia R, Alberti KG, et al. The importance of injury as a cause of death in sub-Saharan Africa: results of a community-based study in Tanzania. Public Health 2001;115:96-102.

12. Moshiro C, Heuch I, Astrom AN, et al. Injury morbidity in an urban and a rural area in Tanzania: an epidemiological survey. BMC Public Health 2005;5:11.

13. Chalya PL, Mabula JB, Dass RM, et al. Pattern of childhood burn injuries and their management outcome at Bugando Medical Centre in Northwestern Tanzania. BMC Res Notes 2011:4:485.

14. Tanzania UR. The United Republic of Tanzania. Population and Housing Census General Report, 2003.

15. Snow RW, Armstrong JR, Forster D, et al. Childhood deaths in Africa: uses and limitations of verbal autopsies. Lancet 1992;340:351-5.

16. Setel PW, Whiting DR, Hemed Y, et al. Validity of verbal autopsy procedures for determining cause of death in Tanzania. Trop Med Int Health 2006;11:681-96.

17. Quigley MA, Armstrong Schellenberg JR, Snow RW. Algorithms for verbal autopsies: a validation study in Kenyan children. Bull World Health Organ 1996;74:147-54

18. Chandramohan D, Maude GH, Rodrigues LC, et al. Verbal autopsies for adult deaths: their development and validation in a multicentre study. Trop Med Int Health 1998;3:436-46.

19. Filmer D, Pritchett LH. Estimating wealth effects without expenditure data-or tears: an application to educational enrollments in states of India. Demography 2001;38:115-32.

20. Vyas S, Kumaranayake L. Constructing socio-economic status indices: how to use principal components analysis. Health Policy Plann 2006:21:459-68.

21. Garrib A, Herbst AJ, Hosegood V, et al. Injury mortality in rural South Africa 2000-2007: rates and associated factors. Trop Med Int Health 2011;16:439-46.
22. Mabunda MM, Swart LA, Seedat M. Magnitude and categories of pedestrian fatalities in South Africa. Accid Anal Prev 2008;40:586-93.

23. Moshiro C, Heuch I, Astrom AN, et al. Effect of recall on estimation of non-fatal injury rates: a community based study in Tanzania. Inj Prev 2005;11:48-52.

24. Roudsari BS, Sharzei K, Zargar M. Sex and age distribution in transport-related injuries in Tehran. Accid Anal Prev 2004;36: 391-8.

25. Moniruzzaman S, Andersson R. Cross-national injury mortality differentials by income level: the possible role of age and ageing Public Health 2008:122:1167-76.

26. Lawlor DA, Sterne JA, Tynelius P, et al. Association of childhood socioeconomic position with cause-specific mortality in a prospective record linkage study of 1839384 individuals. Am J Epidemiol 2006;164:907-15.

27. Cubbin C, LeClere FB, Smith GS. Socioeconomic status and injury mortality: individual and neighbourhood determinants. J Epidemiol Community Health 2000;54:517-24.

28. Cubbin C, Smith GS. Socioeconomic inequalities in injury: critical issues in design and analysis. Annu Rev Public Health 2002;23:349-75.

29. Mbembati N, Maseru L, Leshabari M. Childhood burn injuries in children in Dar es Salaam: patterns and perceptions of prevention: short research article. African Safety Promot 2002;1:42-5.

30. Odero W, Khayesi M, Heda PM. Road traffic injuries in Kenya: magnitude, causes and status of intervention. Inj Control Saf Promot 2003;10:53-61.

31. Mock CN, Forjuoh SN, Rivara FP. Epidemiology of transport-related injuries in Ghana. Accid Anal Prev 1999;31:359-70.

32. Norman R, Matzopoulos R, Groenewald P, et al. The high burden of injuries in South Africa. Bull World Health Org 2007;85:695-702.

33. Seedat $M$, Van Niekerk $A$, Jewkes $R$, et al. Violence and injuries in South Africa: prioritising an agenda for prevention. Lancet 2009;374:1011-22

34. Lerel L. The epidemiology of fatal childhood burns. South Afr Med J 1994;84:169-70.

35. Forjuoh SN. Injury control in developing nations: what can we learn from industrialized countries? Inj Prev 1996:2:90-1.

36. Quan L, Crispin B, Bennett E, et al. Beliefs and practices to prevent drowning among Vietnamese-American adolescents and parents. Inj Prev 2006;12:427-9.

37. Mangione TW, Chow W, Nguyen J. Trends in life jacket wear among recreational boaters: a dozen years (1999-2010) of US observational data. J Public Health Policy 2012;33:59-74.

38. WHO.World Report on Violence and Health. Geneva, 2002.

39. Burrows $\mathrm{S}$, Vaez M, Butchart $\mathrm{A}$, et al. The share of suicide in injury deaths in the South African context: sociodemographic distribution. Public Health 2003;117:3-10.

40. Bowley DM, Parmar NK, Boffard KD. Burdens of disease in southern Africa. Lancet 2004;363:1508.

41. Matzopoulos R, Myers JE, Bowman B, et al. Interpersonal violence prevention: prioritising interventions. S Afr Med J 2008;98:682, 4, 6 passim.

42. Mann JJ, Apter A, Bertolote J, et al. Suicide prevention strategies: a systematic review. JAMA 2005;294:2064-74.

43. Tondo L, Albert MJ, Baldessarini RJ. Suicide rates in relation to health care access in the United States: an ecological study. J Clin Psychiatry 2006;67:517-23.

44. Manoranjitham SD, Rajkumar AP, Thangadurai P, et al. Risk factors for suicide in rural south India. Br J Psychiatry 2010;196:26-30.

45. Encyclopedia of the Nations. Encyclopedia of the Nations. http://www. nationsencyclopedia.com/economies/Africa/ Tanzania-INFRASTRUCTURE-POWER-AND-COMMUNICATIONS.htm (accessed 16 Aug 2012)

46. Kahn K, Tollman SM, Collinson MA, et al. Research into health, population and social transitions in rural South Africa: data and methods of the Agincourt Health and Demographic Surveillance System. Scand J Public Health Supp/ 2007;69:8-20.

47. Tollman S, Kark S, Kark E. The Pholela Health Centre: Understanding health and disease in South Africa through Community-Oriented Primary Care (COPC). In: Das Gupta M, Aaby $\mathrm{P}$, Pison G, Garenne M.eds. Prospective community studies in developing countries. Oxford: Clarendon Press, 1997:213-32. 